УДК $577.1,579.6$

\title{
ВЛИЯНИЕ ЭКСТРАКТОВ РАСТЕНИЙ И ОТДЕЛЬНЫХ МЕТАБОЛИТОВ НА ОБРАЗОВАНИЕ БИОПЛЕНОК (ОБЗОР)
}

\author{
(C) М.А. Живетьев ${ }^{1,2 *}$, Ю.А. Маркова ${ }^{1,2,3}$, И.А. Граскова ${ }^{1,3}$ \\ ${ }^{1}$ Сибирский институт фризиологии и биохимии растений, \\ ул. Лермонтова, 132, Иркутск, 664033 (Россия), e-mail: nik.19@mail.ru \\ ${ }^{2}$ Иркутский национальный исследовательский технический университет, \\ ул. Лермонтова, 83, Иркутск, 664074 (Россия) \\ ${ }^{3}$ Иркутский научный центр, ул. Лермонтова, 134, Иркутск, 664033 (Россия)
}

В обзоре рассмотрены различные регуляторы развития бактериальных биопленок. Уделено отдельное внимание эфирным маслам и экстрактам, их фракциям и конкретным соединениям лекарственных, пищевых и кормовых растений. Раскрыт ряд механизмов их воздействия на коллективное поведение микроорганизмов. Продуцируемые растениями соединения могут не только оказывать прямое токсическое действие на бактериальные клетки, но и выступать регуляторами экспрессии генов устойчивости к антибиотикам и генов их биосинтеза, а также широкого спектра генов, активизирующихся при переходе от свободного планктонного существования к прикрепленному. Рассмотренные активности экстрактов растений и их отдельных метаболитов распространяются не только на грамотрицательные и грамположительные бактерии, но и на другие микроорганизмы, включая дрожжи, что расширяет возможности их практического применения. Синергичные с антибиотиками эффекты растительных метаболитов и способность их эффективно блокировать чувство кворума бактерий и возможность их к адгезии позволяют рассматривать экстракты растений и отдельные соединения растительного происхождения как перспективные в борьбе с инфекционными процессами, обусловленными способностью бактерий формировать биопленки. По большому счету в любом из известных высших и низших растений могут содержаться вещества антибактериального действия, нарушающие стратегию коллективного поведения микроорганизмов и препятствующие колонизации тканей и клеток растений патогенной микрофлорой. Бактерицидные, бактериостатические и антибиопленочные эффекты могут существенно отличаться даже в случае соединений близкой химической природы, а одно и то же вещество может одновременно выступать регулятором разных механизмов.

Ключевые слова: экстракты растений, растительные метаболиты, влияние на микроорганизмы, биопленки, чувство кворума.

Работа выполнена при поддержке интеграџионной программы «Фундаментальные исследования и прорывные технологии как основа опережающего развития Байкальского региона и его межрегиональных связей».

\section{Введение}

Растительные метаболиты определяют характер растительно-микробных взаимодействий и способны вызывать как ингибирующее, так и стимулирующее воздействие на определенные виды бактерий и бактериальные сообщества [1]. В свою очередь, и бактерии воздействуют на метаболизм растений. При этом наиболее эффективным способом освоения новых экологических ниш для бактерий является, по всей видимости, образование биопленок. При определенных условиях клетки микроорганизмов адгезируются

Живетьев Максим Аркадьевич - кандидат биологических наук, научный сотрудник, e-mail: nik.19@mail.ru Маркова Юлия Александровна - доктор биологических наук, заведующая лабораторией растительно-микробных взаимодействий, e-mail: juliam06@mail.ru

Граскова Ирина Алексеевна - доктор биологических наук, главный научный сотрудник, e-mail: graskova@sifibr.irk.ru на биологических или искусственных поверхностях, на которых растут, размножаются и синтезируют полисахаридный матрикс с образованием высокоупорядоченного сообщества, как раз и получившего называние биопленки [2, 3]. Матрикс биопленок, кроме полисахаридов, может включать белки и нуклеиновые кислоты и обусловливает резистентность

\footnotetext{
* Автор, с которым следует вести переписку.
} 
к антибиотикам и факторам иммунной защиты человеческого или растительного организма $[4,5]$. Состояние биопленки позволяет эффективно колонизировать организмы, в том числе организм человека, приводя к хронизации большинства инфекционных заболеваний, а возможность формирования межвидовых сообществ в биопленках наряду с высокой антибиотикорезистентностью многих патогенных и условнопатогенных микроорганизмов делает их практически неуязвимыми [6, 7]. В связи с этим поиск агентов, способных разрыхлять и разрушать биопленочные образования, переводя бактерии в состояние, более восприимчивое к антибактериальным и бактериостатическим препаратам, безусловно, актуален [8].

\section{Основная часть}

Учитывая, что биопленка в своем развитии проходит несколько стадий: образования, созревания и распространения, - поиск веществ, эффективно воздействующих на бактерии, ведется для каждой из них.

Любое сообщество микроорганизмов переходит к биопленкообразованию в ответ на действие определенных факторов внешней среды: $\mathrm{pH}$, температуры, осмолярности и сопровождается изменением метаболизма, водного обмена, коммуникативных связей и т.д. составляющих его клеток [5]. В свою очередь, в уже образовавшейся биопленке кардинально меняются многие физиологические процессы, и в первую очередь усиливается синтез метаболитов и биологически активных соединений, направленный как на формирование матрикса, так и на образование информационных связей между бактериальными клетками и внешней средой [3]. Социальное поведение бактерий, в том числе в составе биопленки, получило название quorum sensing (QS), или чувство кворума. Под QS подразумевают разветвленную сеть сигналов, из которых наиболее изучены ацилгомосеринлактонная сигнальная система (АГЛ) и система аутоиндуктора второго типа (AI-2) [9]. В то же время, несмотря на достаточно длительную историю изучения этого вопроса (высокий интерес к биопленкам возник в начале 2000-х гг. и не утихает до сих пор), в процессах формирования микробных биопленок до сих пор остается много неизвестного. Причина кроется в сложной многоступенчатой регуляции биопленкообразования, которая осуществляется как факторами внешней среды, так и состоянием самой популяции бактерий.

Биопленочное сообщество рано или поздно достигает наивысшего уровня развития, и стадия созревания биопленки сменяется стадией распространения. В таком случае чаще всего наблюдают явление сворминга (swarming) - коллективного перетекания бактерий в поисках новых источников питания и свободных экологических ниш. В состоянии сворминга бактериальные клетки перемещаются, организуясь параллельно своей оси, чтобы увеличить межклеточный контакт. При этом они претерпевают существенные морфологические изменения: клетки удлиняются, увеличивается число флагелл, существенно изменяется состав полисахаридного матрикса, который при перемещении бактерий никуда не исчезает, но обогащается рамнолипидами (Pseudomonas), сурфактином (Bacillus), или серраветтином (Serratia), снижающими поверхностное натяжение при движении и защищающими от внешних воздействий, в том числе действия антибиотиков [10]. В то же время показано, что ингибирование сворминга $S$. marcescens и формирование им биопленки сопряжено с отсутствием серравитина, а высокие уровни содержания рамнолипидов препятствуют формированию биопленок P. aeruginosa [11]. На сегодняшний день сворминг выявлен у различных представителей родов Proteus, Vibrio, Bacillus, Clostridium, Chromobacterium, Escherichia, Salmonella, Azospirillum, Aeromonas, Yersinia, Serratia, Burkholderia, Pseudomonas, Sinorhizobium [10]. Состояние сворминга изучено не так хорошо, как биопленки, но есть все основания считать, что при патогенезе сворминг играет важную роль. Существует способ «размножения» биопленок через свимминг - миграцию одиночных клеток с последующим созданием новых биопленочных сообществ.

Препятствование росту и делению бактерий, а также нарушение поверхностных свойств клеток и разрушение их стенок - эти антимикробные свойства проявляются наиболее ярко на одиночных клетках. Негативное же воздействие различных агентов на биопленки можно охарактеризовать следующим образом: блокирование способности клеток к адгезии к субстрату, что препятствует началу биопленкообразования, нарушение чувство кворума бактерий, что приводит к разрушению уже формируемой биопленки, и наконец, негативное влияние на подвижность клеток, препятствование их расселению и свормингу.

Растения, которые, защищая себя, накапливают разнообразные вторичные метаболиты с антимикробным действием, являются природным резервуаром подобных веществ. Изучение воздействия этих соединений в дальнейшем может существенно расширить наши возможности в регуляции многоклеточного поведения бактерий [12]. Не удивительно, что растения издавна используются как источники лекарствен- 
ных средств в народной и современной медицине. Считается, что из известных порядка 400 тыс. видов высших растений химический состав изучен менее чем у 10\%. Поскольку, по сути, все растения являются лекарственными - и не только высшие, но и низшие - и любые из них могут содержать до тысячи перспективных для использования веществ, становится очевидно, что их потенциал как источника новых лекарственных соединений практически безграничен [13].

Следует различать действие суммарных экстрактов лекарственных растений и отдельных соединений растительного происхождения на бактерии и их сообщества. Если такие растительные метаболиты,ю как флавоноиды, алкалоиды и терпены, чаще всего обладают выраженной антимикробной активностью $[14,15]$, то сахара и аминокислоты могут, наоборот, способствовать росту колоний микроорганизмов [13].

Например, в надземной части сюссюреи Saussurea controversa содержится 3,7-6,5\% сахаров [16], в водных экстрактах рода фиалок (Viola) может находиться 6-10\% поли- и моносахаридов, а белков и аминокислот - до 3\% от массы сухого растительного сырья [17-19]. Влияние этих компонентов растительных экстрактов нельзя исключать.

Дополнительным нюансом, усложняющим исследования в обозначенном направлении, является то, что даже одна фенольная составляющая экстрактов лекарственных растений одновременно с бактерицидным действием часто обладает антиоксидантным эффектом [20]. Самойлова (2009) в своих работах показала выраженное антиоксидантное действие на E. coli при пероксидном стрессе экстрактов ряда видов растений, причем их антиоксидантная активность положительно коррелировала с содержанием полифенолов в тканях in vivo и in vitro, которые защищали ДНК бактерий от окислительных повреждений. В то же время некоторые экстракты in vitro обладали, наоборот, прооксидантным действием, продуцируя перекись водорода [21]. Yasuko Sakihama с соавторами (2002) акцентируют внимание на том, что растительные фенолы обладают и антиоксидантным, и токсическим эффектами одновременно [22].

Отдельно изучаются перспективы использования в качестве антимикробных агентов эфирных масел, обладающих выраженным бактерицидным действием [23]. Так, масла лаванды и корицы в концентрации всего 0,025\% обладают бактериостатическим действием на Staphylococcus aureus, повышение их концентрации до 0,25\% показывает ингибирующий эффект, а концентрация масел 2,5\% является для этого микроорганизма летальной [24]. Эфирные масла ряда декоративных растений препятствовали образованию биопленок бактериями родов Salmonella, Listeria, Pseudomonas, Stahylococcus и Lactobacillus [13]. Недавно было выяснено, что эфирные масла способны ингибировать транскрипцию FtsZ-белка - важного составляющего бактериального цитоскелета, ответственного за инициацию деления клеток и являющегося ГТФ-зависимой гуанозиттрифосфатазой, подключающей к процессу деления другие белки и ферменты. В случае потери его активности бактерии сливаются в цепочки, происходит нарушение клеточных стенок и их разрушение [25]. Аналогичный эффект наблюдали, действуя основными составляющими этих эфирных масел: коричным альдегидом, преобладающим в масле корицы, и линалоолом - мажорным компонентом в масле лаванды [24]. Для этих соединений были выявлены минимальные концентрации 6,25 и 50 мг/л соответственно, ингибирующие рост $S$. aureus. Сходным образом коричный альдегид влиял на E.coli [26] и Bacillus cereus [27]. Другими авторами [28] показано, что коричная кислота способна также ингибировать ферменты, осуществляющие поглощение глюкозы и синтез АТФ у S. aureus. Rastogi с соавторами [29] на E.coli продемонстрировали, что из ряда фенольных соединений наилучшим ингибитором FtsZ является транс-коричная кислота, а наихудшим - 4-формил коричная. Эвгенол, нарингенин и кофейная кислота показали среднюю ингибирующую активность. К веществам, способным нарушать функциональность белка FtsZ, относят также куркумин, виридитоксин, дихаментин, тотарол, сангвинарин, берберин, хризофаентины - не считая целого ряда синтетических соединений $[25,30]$.

Экстракты ванили (Vanilla planifolia) [31], лавра (Laurus nobilis), осота (Sónchus oleraceus), розмарина (Rosmarinus officinalis) и жасмина (Jasmínum sambac) [32], чеснока (Állium satívum), ананаса (Ananas comosus), банана (Musa paradiciaca) и саподиллы (Manilkara zapota) [13] блокируют чувство кворума ряда бактерий, нарушая проявление регулируемых им признаков. Экстракты брокколи могут ингибировать экспрессию генов, ассоциированных с QS, тем самым ингибируя вирулентность E. coli O157:Н7. Поэтому антиинфекционный потенциал брокколи перспективно использовать при составлении рационов в диетологии [13].

Хлороформные, гексановые и метанольные экстракты Vernonia blumeoides влияют на QS-регулирующие протеины CviR и CviR' опосредованно через лактон, что снижает вирулентность и патогенность антибиотикорезистентных бактерий $C$. violaceum и A. tumefaciens [33]. Allison Adonizio с соавторами [34] 
на C. violaceum и A. tumefaciens показали анти-QS активность у шести из 50 лекарственных растений Флориды. Их эффективность была сопоставима с галогенированными фуранонами, тетрациклином и гептамицином, использованными для сравнения, и сохранялась при любых способах экстракции: водной, спиртовой, из свежих и высушенных тканей.

Растения могут манипулировать системой чувства кворума бактерий, воздействуя на их способность формировать биопленки, синтезировать факторы вирулентности или другие соединения, находящиеся под контролем этой системы. Такой эффект достигается несколькими путями, включая синтез веществ, обладающих сходной химической структурой с сигналами QS и/или способности деградировать рецепторы аутоиндукторов (LuxR/LasR) [13]. В этой связи видится немаловажным потенциал лекарственных растений как источников не только антимикробных агентов, но и возможных регуляторов коллективного поведения бактерий $[35,36]$. Быстрое увеличение числа ингибиторов чувства кворума, изолированных из эукариот, подчеркивает перспективность дальнейшего поиска соединений, способных управлять коммуникативной способностью бактерий, тем самым снижая их вирулентность и способность к многоклеточному поведению.

Структура большинства растительных молекул, создающих помехи чувству кворума бактерий, пока неизвестна. Наиболее охарактеризованы соединения, имитирующие химическую структуру аутоиндукторов, - галогенированные фураноны из красной водоросли Delisea pulchra [9]. Выявлено, что бромированные фураноны являются ковалентными ингибиторами синтазы АГЛ, LuxS [37] и полностью ингибируют движение по типу сворминга и формирование биопленок у E. coli [38].

Особо следует выделить фенольные соединения растений, многие из которых демонстрируют способность воздействовать на QS.

Растительный флавон лютеолин играет регуляторную роль в образовании клубеньков ризобия, индуцируя гены их формирования, что контрастирует с функцией флавоноидов как соединений, выполняющих защитную роль [39]. Очевидно, симбиотическая и прочая полезная для растений микробиота не подвергается атаке фенольных и других бактерицидных соединений, в отличие от патогенной микрофлоры.

Экстракты Acacia nilotica, богатые галловой, кофейной, ферруловой кислотами, изокверцетином, кемпферолом, нарингенином, рутином, апигенином, галлотанинами и многими другими фенольными соединениями, показали анти-QS активность относительно Chromobacterium violaceum (АТCC 12474). Причем ингибирующий эффект был всегда выше по сравнению с теми же концентрациями кверцетина, использованного как стандарт бактерицидного действия флавоноидов [40].

Токоферрол, используемый как стандарт, и фенолосодержащие экстракты тысячелистника Achillea santolina ингибировали на 96,06 и 73,33\% соответственно пероксидное окисление липидов, вызванное Fе ${ }^{2+}$ и аскорбатом [41], что защищает в том числе и растительные клетки при патогенном стрессе.

Ингибирующую активность на Bacillus cereus и B. cereus ATCC 10987 показали растения традиционной медицины Эфиопии, имеющие в своем составе биомолекулы, воздействующие на межклеточные коммуникации микроорганизмов [42].

C синтезируемым P. aeruginosa RAO1, активным против всех грамположительных бактерий антибиотиком, пиоцианином, связывают ингибирующий на 40-70\% эффект этого возбудителя на условнопатогенные микроорганизмы человека [43]. Алкалоид платифиллин, содержащий в крестовиках Senecio ssp., влияет на продукцию ацил-гомосерин лактона у P. aeruginosa RAO1 [43] и на биосинтез пиоцианина, который находится под контролем QS-системы. Анти-QS потенциал платифиллина успешно протестирован на C. violaceum CV026.

Природные фитоалексины стилбеноиды, из которых наиболее известен ресвератрол, выделяемый некоторыми растениями для защиты от бактериальных и грибковых инфекций, обладают противоопухолевым, противовоспалительным действием. Ресвератрол, оксиресвератрол и пайситаннол статистически достоверно останавливали синтез виолацеина у C. violaceum CV026 и QS-регулируемых факторов вирулентности $P$. aeruginosa RAO1, выработку пиоцианина, сворминг и экспрессию QS-регулируемых генов $P$. aeruginosa RAO1 [44].

Флавоноидная фракция листьев Psidium guajava ингибировала продукцию пиоцианина, протеолитическую и эластолитическую активность, сворминг и способность образовывать биопленки у P. aeruginosa PAO1, а у Chromobacterium violaceum АТСС 12472 - продукцию природного антибиотика виолацеина за счет присутствия кверцетина и кверцетина-3-0-арабинозида в этой фракции, при этом не влияя на синтез гомосеринлактона [45]. Отдельно было показано, что кверцетин и кверцетин-3-0-арабинозид в концентра- 
циях 50 и 100 мг/мл соответственно ингибируют продукцию виолацеина у C. violaceum 12472 [45]. Те же авторы [46] на этанольных экстрактах травы Centella asiatica показали ингибирование QS у C. violaceum CV026 и продукции пигмента виолацеина у C. violaceum 12472. Этилацетатная фракция экстракта С. asiatica, богатая кемпферолом, показала зависимое от концентрации ингибирование QS-регулируемого фенотипа: продукцию пиоцианина, эластолитическую и протеолитическую активность, способность к свормингу и формированию биопленок у P. aeruginosa RAO1.

Недавно выяснено, что розмариновая кислота может выступать подобно гомосерин лактону в качестве молекулы, выполняющей функцию QS-сигналинга, но продуцируемой растениями [47]. Причем розмариновая кислота стимулировала QS-зависимую экспрессию и транскрипцию генов у P. aeruginosa RAO1 сильнее, чем N-бутаноил гомосерин лактон, и запускала формирование биопленок, продукцию факторов вирулентности - эластазу и пиоцианин.

Исследование богатых танинами лекарственных растений Индии показало их активность относительно грамположительных и грамотрицательных бактерий. Шесть из 12 обследованных экстрактов из этих растений обладали анти-QS активностью на C. violaceum 12472 и $S$. aureus [48]. Танины этих экстрактов концентрационнозависимо воздействовали на QS-механизмы через ацилгомосерин лактон.

Водная лилия Nymphaea tetragona, богатая фенолами, танинами и способная к быстрой полимеризации фенольных соединений [49], показала выраженный антиинфекционный потенциал, а ее 50\% метанольные экстракты ингибировали QS-контролируемые факторы вирулентности бактерий, что позволило рекомендовать водную лилию к применению в антибактериальной терапии [50]. Ее экстракты подавляли синтез пигмента виолацеина у C. violaceum и сворминг, формирование биопленок, продукцию пиоцианина и LasA протеиназную активность $P$. aeruginosa, не оказывая цитотоксического эффекта на животные клетки [50].

Протоцианидин снижал выработку факторов вирулентности P. aeruginosa RAO1 и препятствовал полному инфицированию мушек дрозофилы Drosophila melanogaster [51].

Такие фенольные метаболиты, как салициловая кислота, стимулируют экспрессию фермента АГЛлактоназы, осуществляющей разрушение лактонового кольца [12]. Гамма аминомасляная кислота, продуцируемая некоторыми растениями, в экспериментах с фитопатогеном A. tumefaciens способствовала деградации АГЛ лактоназой, тем самым ограничивая зависимый от чувства кворума инфекционный процесс [52]. Ранее Muller с соавторами [53] выявили, что внесение 5 мМ салициловой кислоты в среду ингибировало и рост, и формирование биопленок Staphylococcus epidermidis до 55\%. Исследованиями Jagani et al. показано, что фенольные соединения значительно снижали формирование биопленок Pseudomonas aeruginosa [54]. Действие фенольных соединений на биопленки было подтверждено Borges et al., который обнаружил, что галловая и феруловая кислоты ингибировали подвижность и предотвращали формирование биопленок E. coli, L. monocytogenes, P. aeruginosa и $S$. aureus [55]. Урсулиновая кислота (10 мг/мл) была способна снижать формирование биопленок E. coli на 79\% и V. harveyi и P. aeruginosa PAO1 на 57-95\% [13].

Капсаицин, дигидрокапсаицин и кризоэриол, выделенные из экстрактов перца Capsicum frutescens оказывали антимикробное действие на грамположительные Enterococcus faecalis, Bacillus subtillis, S. aureus, грамотрицательные Pseudomonas aeruginosa, Klebsiella pneumoniae, E. coli, а также на дрожжи Candida albicans [20].

В благоприятных условиях бактерии имеют отрицательный поверхностный заряд, но при экспозиции с фенольными кислотами поверхностный заряд бактерий значительно увеличивается, особенно сильно это показано для B. cereus [56]. Гидрофильность клеточной поверхности препятствует колонизации тканей хозяина, поэтому экстракты G. odoratum и U. dioica авторы предлагают применять при лечении инфекций мочевыводящих путей, вызванных E. coli [57]. Таким образом, синтезируемые растениями соединения способны существенно влиять на физико-химические свойства поверхности микробной клетки.

Присутствие фимбриальных адгезинов способствует прикреплению бактериальных клеток к тканям хозяина, а курлии играют важную роль в формировании биопленок представителями семейства Enterobacteriaceae [58]. Показано, что экстракты березы (Betula pendula), крапивы двудомной (U. dioica) и клюквы (Vaccinium vitis-idaea) ингибируют гемагглютинацию эритроцитов уропатогенными $E$. coli, что указывает на дисфункцию фимбрий Р-типа [59]. Предположительно эти соединения связывают фимбрии и тем самым предотвращают их прикрепление к тканям хозяина. E. coli, растущая в присутствии сока клюквы, снижала образование фимбрий Р-типа, что приводило к неспособности колонизировать эпителиальные клетки мочевого пузыря [60]. Gupta с коллегами [61] наблюдал ингибирование адгезии к клеткам уро- 
эпителия полирезистентными E. coli, обработанными проантоцианидинами. Редукция пилей напрямую коррелировала с отсутствием способности уропатогенных штаммов E. coli колонизировать клетки мочевого пузыря и формировать биопленки [62]. Выращивание бактерий при разных концентрациях экстракта клюквы ( $V$. vitis-idaea) и при высоких концентрациях экстрактов хвоща полевого (Equisetum arvense) (10,020,0 мг/мл) приводило к прекращению экспрессии генов, кодирующих фимбрии Р-типа [57].

Показано, что продукты метаболизма растений могут использоваться для улучшения терапевтической эффективности антибиотиков [63]. Например, водные экстракты растения кат (Catha edulis) усиливают действие тетрациклина на Streptococcus sanguis TH-13 и Streptococcus oralis SH-2, а также пенициллина G на Fusobacterium nucleatum [64]. Этанольные экстракты растений вайды красильной (Isatis tinctoria), шлемника байкальского (Scutellaria baicalensis) и ревеня (Rheum palmatum) увеличивали активность ципрофлоксацина, пенициллина, гентамицина и цефтриаксона против антибиотикорезистентных штаммов S. aureus [65], а этанольные экстракты суринамской вишни (Eugenia uniflora) и родственного ей растения Eugenia jambolanum действуют синергично с гентамицином на E. coli [63].

Немаловажно влияние растительных метаболитов на функционирование и синтез нуклеиновых кислот в клетках патогенной микрофлоры. Показано, что флавонол мерицетин, присутствующий во многих овощах, травах, ягодах и фруктах, ингибирует ДНК-хеликазу, ряд ДНК- и РНК-полимераз, обратную транскриптазу и теломеразу E. coli [66].

\section{Заключение}

На сегодня убедительно доказано, что экстракты растений или их отдельные соединения действуют как на чувство кворума бактерий [13], так и на их способность к адгезии [57], на поверхностные свойства клеток [32, 56], на их подвижность [56, 57], экспрессию генов, участвующих в биопленкообразовании [57]. Есть многочисленные сведения, что растительные метаболиты способны действовать синергично с антибиотиками, ингибируя процессы их выведения из клетки - эффлюкса [63].

Некоторые наиболее значимые эффекты компонентов растительных извлечений дополнительно представлены в таблице.

Влияние агентов растительного происхождения на микроорганизмы

\begin{tabular}{|c|c|c|c|}
\hline Соединение & Микроорганизм & Механизм действия & Источник \\
\hline $\begin{array}{c}\text { Природные и синтетические фла- } \\
\text { воноиды }\end{array}$ & Staphylococcus aureus & $\begin{array}{c}\text { Препятствует образованию био- } \\
\text { пленок }\end{array}$ & {$[67]$} \\
\hline $\begin{array}{l}\text { Флавоноиды клюквы, такие как } \\
\text { проантоцианидины и мирицетин }\end{array}$ & Streptococcus mutans & Ингибирует способность к адгезии & [68] \\
\hline Проантоцианидины & Candida albicans & Ингибирует рост планктонной & [69] \\
\hline Stryphnodendron adstringens & & $\begin{array}{c}\text { культуры и образование биопленок } \\
\text { C. albicans }\end{array}$ & \\
\hline $\begin{array}{l}\text { Тритерпены и флавоноиды Ficus } \\
\text { sansibarica Warb. subsp. sansibarica }\end{array}$ & $\begin{array}{l}\text { S. aureus } \\
\text { ATCC } 29213 \text {, } \\
\text { Escherichia coli } \\
\text { ATCC } 25922\end{array}$ & Препятствует адгезии & {$[70]$} \\
\hline Флоретин, яблочный флавоноид & E. coli $\mathrm{O} 157: \mathrm{H} 7$ & $\begin{array}{c}\text { Снижает продукцию фимбрий, } \\
\text { репрессирует экспрессию генов } \\
h l y E, s t x_{2} .\end{array}$ & {$[71]$} \\
\hline Проантоцианидины клюквы & C. albicans & $\begin{array}{c}\text { Снижает образование биопленок, } \\
\text { ингибируя адгезию к силикону и } \\
\text { полистиролу }\end{array}$ & {$[72]$} \\
\hline $\begin{array}{l}\text { Эллаговая кислота и ее производ- } \\
\text { ные из Rubus ulmifolius Schott. } \\
\text { (Rosaceae) }\end{array}$ & S. aureus & $\begin{array}{c}\text { Ингибирует формирование био- } \\
\text { пленок S. aureus, увеличивая чув- } \\
\text { ствительность к ряду антибиотиков }\end{array}$ & {$[73]$} \\
\hline $\begin{array}{l}\text { Производные олеаноловой кислоты } \\
\text { из Dalbergia trichocarpa }\end{array}$ & $\begin{array}{l}\text { Pseudomonas } \\
\text { aeruginosa } \mathrm{PAO} 1\end{array}$ & $\begin{array}{c}\text { Ингибирует формирование био- } \\
\text { пленок. Снижает экспрессию генов } \\
\text { las и rhl системы QS }\end{array}$ & {$[74]$} \\
\hline $\begin{array}{l}\text { Алкалоид соленопсин А из } \\
\text { Solenopsis invicta }\end{array}$ & P. aeruginosa & $\begin{array}{c}\text { Ингибирует продукцию пиоциани- } \\
\text { на P. Aeruginosa, вероятно, из-за } \\
\text { нарушения rhl системы сигналлин- } \\
\text { га, снижает образование биопленок }\end{array}$ & {$[75]$} \\
\hline
\end{tabular}


Окончание таблицы

\begin{tabular}{|c|c|c|c|}
\hline Соединение & Микроорганизм & Механизм действия & Источник \\
\hline $\begin{array}{l}\text { Розмариновая кислота из Осітит } \\
\text { basilicum L. }\end{array}$ & P. aeruginosa & $\begin{array}{c}\text { Препятствует формированию } \\
\text { биопленок, ингибирует QS }\end{array}$ & {$[76]$} \\
\hline Фурокумарины из сока грейпфрута & Vibrio harveyi & $\begin{array}{c}\text { Ингибирует активность аутоиндук- } \\
\text { торов AI-1 и AI-2 }\end{array}$ & [77] \\
\hline Байкалеин из Scutellaria & E. coli, & Способствует протеолизу белка & {$[78]$} \\
\hline baicalensis Georgi & P. aeruginosa & $\begin{array}{c}\text { TraR Escherichia coli, ингибирует } \\
\text { формирование биопленок } \\
\text { P. aeruginosa }\end{array}$ & \\
\hline Эмодин из Rheum palmatum L. & P. aeruginosa & $\begin{array}{c}\text { Ингибирует формирование } \\
\text { биопленок }\end{array}$ & {$[79]$} \\
\hline Полифенолы из & P.aeruginosa & Ингибирует формирование & [80] \\
\hline $\begin{array}{l}\text { Meliaceae, Melastomataceae, Lepido } \\
\text { botryaceae, и Sapindaceae, }\end{array}$ & PA14 & биопленок & \\
\hline Ахоен из Allium sativum L. & P. aeruginosa & $\begin{array}{c}\text { Воздействует на гены, регулируе- } \\
\text { мые QS, включая продукцию } \\
\text { рамнолипидов }\end{array}$ & [81] \\
\hline $\begin{array}{l}\text { Экстракты гинкго (Zingiber } \\
\text { officinale Rosc.) }\end{array}$ & P. aeruginosa $\mathrm{PA} 14$ & $\begin{array}{c}\text { Ингибирует формирование био- } \\
\text { пленок через снижение продукции } \\
\text { c-di-GMP и последующее сниже- } \\
\text { ние количества продукции полиса- } \\
\text { харидов }\end{array}$ & {$[82]$} \\
\hline $\begin{array}{l}\text { Дитерпены из этанольного экстрак- } \\
\text { та Croton nepetaefolius Baill }\end{array}$ & P. aeruginosa & $\begin{array}{c}\text { Ингибирует формирование } \\
\text { биопленок }\end{array}$ & [83] \\
\hline $\begin{array}{l}\text { Урсуловая кислота из Diospyros } \\
\text { dendo }\end{array}$ & $\begin{array}{l}\text { E. coli, } \\
\text { P. aeruginosa, } V \text {. } \\
\text { harveyi }\end{array}$ & $\begin{array}{c}\text { Ингибирует формирование био- } \\
\text { пленок }\end{array}$ & [84] \\
\hline $\begin{array}{l}\text { Эпигаллокатехин-3-галлат из зеле- } \\
\text { ного чая }\end{array}$ & $\begin{array}{l}\text { Stenotrophomonas } \\
\text { maltophilia }\end{array}$ & $\begin{array}{c}\text { Ингибирует формирование био- } \\
\text { пленок, и также количество живых } \\
\text { клеток в молодых и зрелых био- } \\
\text { пленках }\end{array}$ & [85] \\
\hline $\begin{array}{l}\text { Эфирные масла и метанольный } \\
\text { экстракт из средиземноморской } C \text {. } \\
\text { sempervirens L. }\end{array}$ & Klebsiella pneumoniae & $\begin{array}{c}\text { Обладает антимикробным и анти- } \\
\text { биопленочным действием }\end{array}$ & [86] \\
\hline Ализарин, перпурин и хинализарин & S. aureus & $\begin{array}{c}\text { Ингибирует гемолитическую } \\
\text { активность }\end{array}$ & [87] \\
\hline
\end{tabular}

Поэтому поиск новых агентов для борьбы с возбудителями заболеваний человека, домашних животных и хозяйственно значимых растений продолжается, а экстракты растений и отдельные продукты их метаболизма достойны внимания как перспективные средства борьбы с бактериальными биопленками. Они могут действовать, не уничтожая микробные клетки, как это делают антибиотики, а селективно изменяя их поведение, что достигается в первую очередь за счет взаимодействия с системой чувства кворума. Этого вполне достаточно, чтобы предотвратить хронизацию воспалительного процесса за счет скопления клеток патогенов в биопленки, что необходимо для полного выздоровления без возникновения осложнений после болезни. В то же время вещества растительного происхождения могут усиливать воздействие антибиотиков, снижая их минимальную ингибирующую концентрацию, в результате способствуя разрушению уже образованных биопленок, а следовательно, и очага воспаления. Существенным достоинством продуктов растительного происхождения является их, в большинстве случаев, слабая токсичность для человека. Все вышесказанное свидетельствует о том, что изучение биологически активных соединений, синтезируемых растениями, может привести к открытию новых способов управления многоклеточным поведением бактерий, что еще усовершенствует наши возможности в борьбе с болезнями.

\section{Список литературы}

1. Bogino P.C., M. de la Mercedes Oliva, F.G. Sorroche, W. Giordano. The role of bacterial biofilms and surface components in plant-bacterial associations // Int. J. Mol. Sci. 2013. N 14. Pp. 15838-15859.

2. Aparna M.S., Yadav S. Biofilms: microbes and disease // Dranz. J. Infect. Dis. 2008. Vol. 12 (6). Pp. 526-530. 
3. Хренов П.А., Честнова Т.В. Обзор методов борьбы с микробными биопленками при воспалительных заболеваниях // Вестник новых медицинских технологий. 2013. №1. Электронное издание.

4. Ильина Т.С., Романова Ю.М., Гинцбург А.Л. Биопленки как способ существования бактерий в окружающей среде и организме хозяина: феномен, генетический контроль и системы регуляции их развития // Генетика. 2004. № 40. C. 1-12.

5. Романова Ю.М., Гинцбург А.Л. Бактериальные биопленки как естественная форма существования бактерий в окружающей среде и в организме хозяина // Журнал микробиологии, эпидемиологии и иммунобиологии. 2011. № 3. С. 99-109.

6. Гостев В.В., Сидоренко С.В. Бактериальные биопленки и инфекции // Журнал инфектологии. 2010. Т. 2 . № 3. C. 4-15.

7. Толордава Э.Р., Перепанова Т.С., Егамбердиев Д.К., Романова Ю.М. Изучение процесса образования биопленки патогенными микроорганизмами на поверхности почечных камней // Клиническая лабораторная диагностика. 2010. № 9. С. 31-32.

8. Голуб А.В. Бактериальные биопленки - новая цель терапии? // Клиническая микробиология и антимикробная химиотерапия. 2012. Т. 14. № 1. С. 23-29.

9. González J.E., Keshavan N.D. Messing with bacterial quorum sensing // Microbiology and Molecular Biology Reviews. 2006. Vol. 70 (4). Pp. 859-875.

10. Kearns D.B. A field guide to bacterial swarming motility // Nature Reviews Microbiology. 2010. Vol. 8(9). Pp. 634-644.

11. Daniels R., Vanderleyden J., Michiels J. Quorum sensing and swarming migration in bacteria // FEMS microbiology reviews. 2004. Vol. 28(3). Pp. 261-289.

12. Плюта В.А. Особенности образования биопленок и Quorum Sensing регуляция при действии антибактериальных агентов: дисс. .... канд. биол. наук. Москва, 2014. 152 с.

13. Nazzaro F., Fratianni F., Coppola R. Quorum sensing and phytochemicals // International journal of molecular sciences. 2013. Vol. 14(6). Pp. 12607-12619.

14. Zhang N., Wang D., Liu Y. Effects of different plant root exudates and their organic acid components on chemotaxis, biofilm formation and colonization by beneficial rhizosphere-associated bacterial strains // Plant and Soil. 2014. Vol. 374 (1-2). Pp. 689-700.

15. Храмова Е.П., Цыбуля Н.В., Чиндяева Л.Н. Антимикробная активность летучих соединений и содержание фенольных компонентов у некоторых видов рода Pentaphylloides (Rosaceae) // Растительные ресурсы. 2013. T. 49. C. $598-612$.

16. Авдеева Е.Ю., Краснов Е.А., Семенов А.А. Содержание полисахаридов в надземной части Saussurea controversa Dc // Химия растительного сырья. 2015. № 3. С. 43-48.

17. Бубенчиков Р.А. Фитохимическое и фармакологическое изучение растений рода фиалка : автореф. дисс. ... канд. мед. наук. Курск, 2002. 23 с.

18. Мартынов А.М., Даргаева Т.Д. Фенольные соединения и водорастворимые полисахариды фиалки патрэна // Сибирский медицинский журнал. 2009. № 7. С. 213-215.

19. Патент № 2480746 (РФ). Способ количественного определения полисахаридов в траве видов рода фиалка / А.М. Мартынов, Т.Д. Даргаева / 27.04.2002

20. Nascimento P.L.A., Nascimento T.C.E.S., Ramos N.S.M., Silva G.R., Gomes J.E.G., Falcao R.E.A., Moreira K.A., Porto A.L.F., Silva T.M.S. Quantification, antioxidant and antimicrobial activity of phenolics isolated from different extracts of Capsicum frutescens (pimenta malagueta) // Molecules. 2014. Vol. 19. Pp. 5434-5447.

21. Самойлова 3.Ю. Изучение антиоксидантного действия растительных экстрактов на бактерии Escherichia coli : автореф. дисс. ... канд. биол. наук. Пермь, 2009. 159 с.

22. Sakihama Y., Cohen M.F., Grace S.C., Yamasaki H. Plant phenolic antioxidant and prooxidant activities: phenolicsinduced oxidative damage mediated by metals in plants // Toxicology. 2002. Vol. 177. Pp. 67-80.

23. Ethnomedicine: a source of complementary therapeutics / Ed. D. Chattopadhyay, Kerala (India): Research Signpost, 2010.

24. Герман А., Боченек Ж., Герман А.П. Действие масел корицы и лаванды на экспрессию гена FtsZ Staphylococcus aureus ATTC 29213 // Прикладная биохимия и микробиология. 2013. Т. 49. № 5. С. 476-480.

25. Foss M.H., Eun Y.J., Weibel D.B. Chemical biological studies of sub-cellular organization in bacteria // Biochemistry. 2011. Vol. 50 (36). Pp. 7719-7734.

26. Domadia P., Swarup S., Bhunia A., Sivaramon J., Dasgupta D. Inhibition of bacterial cell division protein FtsZ by cinnamaldehyde // Biochem. Pharmacol. 2007. Vol. 74 (6). Pp. 831-840.

27. Kwon J.A., Yu C.B., Park H.D. Bactericidal effects and inhibition of cell separation of cinnamic aldehyde on Bacillus cereus // Lett. Appl. Microbiol. 2003. Vol. 37 (1). Pp. 61-65.

28. Dorantes L., Colmenero R., Hernandez H., Mota L., Jaramillo M.E., Fernandez E., Solano C. Inhibition of growth of some foodborne pathogenic bacteria by Capsicum annum extracts // Intern. Food Microbiol. 2000. Vol. 57 (1-2). Pp. 125-128.

29. Rastogi N., Domadia P., Shetty S., Dasgubta D. Screening of natural phenolic compounds for potential to inhibit bacterial cell division protein FtsZ // Indian J. Exp. Biol. 2008. Vol. 46 (11). Pp. 783-787.

30. Schaffner-Barbero C., Martin-Fontecha M., Chocon P., Andreu J.M. Targeting the assembly of bacterial cell division protein FtsZ with small molecules // ACS Chem. Biol. 2012. Vol. 7 (21). Pp. 1330-1340. 
31. Choo J.H., Rukayadi Y., Hwang J.K. Inhibition of bacterial quorum sensing by vanilla extract // Lett. Appl. Microbiol. 2006. Vol. 42. Pp. 637-641.

32. Brackman G., Hillaert U., van Calenbergh S. Use of quorum sensing inhibitors to interfere with biofilm formation and development in Burkholderia multivorans and Burkholderia cenocepacia // Res. Microbiol. 2009. Vol. 160. Pp. 144-151.

33. Aliyu A.B., Koorbanally N.A., Moodley B., Singh P., Chenia H.Y. Quorum sensing inhibitory potential and molecular docking studies of sesquiterpene lactones from Vernonia blumeoides // Phytochemistry. 2016. Vol. 126. Pp. 23-33.

34. Adonizio A.L., Downum K., Bennett B.C., Kalai M. Anti-quorum sensing activity of medicinal plants in southern Florida // J. of Ethnopharmacology. 2006. Vol. 105. Pp. 427-435.

35. Marcinkiewicz J., Strus M., Pasich E. Antibiotic resistance: a "dark side" of biofilm associated chronic infections // Polskie Archiwum Medycyny Wewnętrznej. 2013. Vol. 123 (6). Pp. 309-313.

36. Ahmad I., Husain F.M., Maheshwari M., Zahin M. Medicinal plants and phytocompounds: a potential source of novel antibiofilm agents // Antibiofilm Agents. Springer Berlin - Heidelberg, 2014. Pp. 205-232.

37. Jimenez-Guerrero P.-M.F.I., Sanchez-Matamoros R.C. Rice and bean AHL-mimic quorum-sensing signals specifically interfere with the capacity to form biofilms by plant-associated bacteria // Research in microbiology. 2013. Vol. 164(7). Pp. 749-760.

38. Ren D., Sims J.J., Wood T.K. Inhibition of biofilm formation and swarming of Escherichia coli by (5Z)-4-bromo-5(bromomethylene)-3-butyl-2 (5H)-furanone // Environmental Microbiology. 2001. Vol. 3 (11). Pp. 731-736.

39. Peters N.K., Frost J.W., Long S.R. A plant flavone, luteolin, induces expression of Rizobium meliloti nodulation genes // Science. 1986. Vol. 233 (4767). Pp. 977-980.

40. Singh B.N., Singh B.R., Singh R.L., Prakash D., Sarma B.K., Singh H.B. Antioxidant and anti-quorum sensing activities of green pod of Acacia nilotica L. // Food and Chemical Toxicology. 2009. Vol. 47. Pp. 778-786.

41. Ardestani A., Yazdanparast R. Antioxidant and free radical scavenging potential of Achillea santolina extracts // Food Chemistry. 2007. Vol. 104. Pp. 21-29.

42. Bacha K., Tariku Y., Gebreyesus F., Zerihun S., Mohammed A., Weiland-Bräuer N., Schmitz R.A., Mulat M. Antimicrobial and anti-Quorum Sensing activities of selected medicinal plants of Ethiopia: Implication for development of potent antimicrobial agents // BMC Microbiol. 2016. Vol. 16. N1. Pp. 139.

43. Ilic-Tomic T., Sokovic M., Vojnovic S., Ciric A., Veljic M., Nikodinovic-Runic J., Novakovic M. Diarylheptanoids from Alnus viridis ssp. viridis and Alnus glutinosa: modulation of Quorum Sensing activity in Pseudomonas aeruginosa // Planta Med. 2017. Vol. 83. Pp. 117-125.

44. Sheng J.Y., Chen T.T., Tan X.J., Chen T., Jia A.Q. The quorum-sensing inhibiting effects of stilbenoids and their potential structure-activity relationship // Bioorg. Med. Chem. Lett. 2015. Vol. 25(22). Pp. 5217-5220.

45. Vasavi H.S., Arun A.B., Rekha P.D. Anti-quorum sensing activity of Psidium guajava L. flavonoids against Chromobacterium violaceum and Pseudomonas aeruginosa PAO1 // Microbiol. Immunol. 2014. Vol. 58, N5. Pp. 286-293.

46. Vasavi H.S., Arun A.B., Rekha P.D. Anti-quorum sensing activity of flavonoid-rich fraction from Centella asiatica L. against Pseudomonas aeruginosa PAO1 // J. Microbiol. Immunol. Infect. 2016. Vol. 49. N1. Pp. 8-15.

47. Corral-Lugo A., Daddaoua A., Ortega A., Espinosa-Urgel M., Krell T. Rosmarinic acid is a homoserine lactone mimic produced by plants that activates a bacterial quorum-sensing regulator// Sci. Signal. 2016. Vol. 9. N409. P. 1.

48. Shukla V., Bhathena Z. Broad spectrum anti-quorum sensing activity of tannin-rich crude extracts of indian medicinal plants // Scientifica (Cairo). 2016. Vol. 2016. P. 5823013.

49. Lavid N., Schwartz A., Yarden O., Tel-Or E. The involvement of polyphenols and peroxidase activities in heavymetal accumulation by epidermal glands of the waterlily (Nymphaeaceae) // Planta. 2001. Vol. 212. Pp. 323-331.

50. Hossain M.A., Lee S.J., Park J.Y., Reza M.A., Kim T.H., Lee K.J., Suh J.W., Park S.C. Modulation of quorum sensing-controlled virulence factors by Nymphaea tetragona (water lily) extract // J. Ethnopharmacol. 2015. Vol. 174. Pp. 482-491.

51. Maisuria V.B., Santos Y.L.L., Tufenkji N., Déziel E. Cranberry-derived proanthocyanidins impair virulence and inhibit quorum sensing of Pseudomonas aeruginosa // Sci. Rep. 2016. Vol. 6. Pp. 30169.

52. Farrand S.K., Qin Y., Oger P. Quorum-sensing system of Agrobacterium plasmids: Analysis and utility // Methods in enzymology. 2002. N358. Pp. 452-484.

53. Muller E., Takeda S., Shiro H. Occurrence of capsular polysaccharide/adhesin among clinical isolates of coagulasenegative staphylococci // J. Infect Dis. 1993. Vol. 168. Pp. 1211-1218.

54. Jagani S., Chelikani R., Kim D.S. Effects of phenol and natural phenolic compounds on biofilm formation by Pseudomonas aeruginosa // Biofouling. 2009. Vol. 25. N4. Pp. 321-324.

55. Borges A., Saavedra M.J., Simões M. The activity of ferulic and gallic acids in biofilm prevention and control of pathogenic bacteria // Biofouling. 2012. Vol. 28. N7. Pp. 755-767.

56. Lemos M., Borges A., Teodosio J. The effects of ferulic and salicylic acids on Bacillus cereus and Pseudomonas fluorescens single-and dual-species biofilms // International Biodeterioration \& Biodegradation. 2014. N86. Pp. 42-51.

57. Wojnicz D., Kucharska A.Z., Sokoł-Łetowska A. Medicinal plants extracts affect virulence factors expression and biofilm formation by the uropathogenic Escherichia coli //Urol. Res. 2012. N40. Pp. 683-697.

58. Zogaj X., Bokranz W., Nimtz M., Römling U. Production of cellulose and curli fimbriae by members of the family Enterobacteriaceae isolated from the human gastrointestinal tract // Infection and immunity. 2003. Vol. 71 . N7. Pp. 4151-4158. 
59. Howell A.B., Vorsa N., Marderosian A.D., Foo L.Y. Inhibition of the adherence of P-fimbriated Escherichia coli to uroepithelial-cell surfaces by proanthocyanidin extracts from cranberries // New England Journal of Medicine. 1998. Vol. 339. N15. Pp. 1085-1086.

60. Ahuja S., Kaack B., Roberts J. Loss of fimbrial adhesion with the addition of Vaccinum macrocarpon to the growth medium of P-fimbriated Escherchia coli // The Journal of urology. 1998. Vol. 159. N2. Pp. 559-562.

61. Gupta A., Dwivedi M., Mahdi A.A. Inhibition of adherence of multi-drug resistant E. coli by proanthocyanidin // Urological research. 2012. Vol. 40. N2. Pp. 143-150.

62. Åberg V., Almqvist F. Pilicides - small molecules targeting bacterial virulence // Organic \& biomolecular chemistry. 2007. Vol. 5. N12. Pp. 1827-1834.

63. Abreu A.C., McBain A.J., Simoes M. Plants as sources of new antimicrobials and resistance-modifying agents // Natural product reports. 2012. Vol. 29. N9. Pp. 1007-1021.

64. Al-hebshi N., Al-haroni M., Skaug N. In vitro antimicrobial and resistance-modifying activities of aqueous crude khat extracts against oral microorganisms // Archives of oral biology. 2006. Vol. 51. N3. Pp. 183-188.

65. Yang Z.C., Wang B.C., Yang X.S. The synergistic activity of antibiotics combined with eight traditional Chinese medicines against two different strains of Staphylococcus aureus // Colloids and surfaces B: Biointerfaces. 2005. Vol. 41. N2. Pp. 79-81.

66. Griep M.A., Blood S., Larson M.A. Myricetin inhibits Escherichia coli DnaB helicase but not primase // Bioorganic \& medicinal chemistry. 2007. Vol. 15. N22. Pp. 7203-7208.

67. Manner S., Skogman M., Goeres D., Vuorela P., Fallarero A. Systematic Exploration of Natural and Synthetic Flavonoids for the Inhibition of Staphylococcus aureus Biofilms // International Journal of Molecular Sciences. 2013. Vol. 14(10). Pp. 19434-19451.

68. Kim D., Hwang G., Liu Y., Wang Y., Singh A.P., Vorsa N., et al. Cranberry Flavonoids Modulate Cariogenic Properties of Mixed-Species Biofilm through Exopolysaccharides-Matrix Disruption // PLoS ONE. 2015. Vol. 10(12). P. e0145844. doi:10.1371/journal.pone.0145844.

69. Luiz R.L.F., Vila T.V.M., de Mello J.C.P., Nakamura C.V., Rozental S., Ishida K. Proanthocyanidins polymeric tannin from Stryphnodendron adstringens are active against Candida albicans biofilms // BMC Complementary and Alternative Medicine. 2015 Vol. 15. N68. doi:10.1186/s12906-015-0597-4.

70. Awolola G.V., Koorbanally N.A., Chenia H., Shode F.O., Baijnath H. Antibacterial and Anti-Biofilm Activity of Flavonoids and Triterpenes Isolated from the Extracts of Ficus Sansibarica Warb. Subsp. Sansibarica (Moraceae) Extracts // African Journal of Traditional, Complementary, and Alternative Medicines. 2014. Vol. 11(3). Pp. 124-131.

71. Lee J.-H., Regmi S.C., Kim J.-A., et al. Apple Flavonoid Phloretin Inhibits Escherichia coli O157:H7 Biofilm Formation and Ameliorates Colon Inflammation in Rats // Payne SM, ed. Infection and Immunity. 2011. Vol. 79(12). Pp. 4819-4827. doi:10.1128/IAI.05580-11.

72. Rane H.S., Bernardo S.M., Howell A.B., Lee S.A. Cranberry-derived proanthocyanidins prevent formation of Candida albicans biofilms in artificial urine through biofilm- and adherence-specific mechanisms // Journal of Antimicrobial Chemotherapy. 2014. Vol. 69(2). Pp. 428-436. doi:10.1093/jac/dkt398.

73. Quave C.L., Estévez-Carmona M., Compadre C.M., et al. Ellagic Acid Derivatives from Rubus ulmifolius Inhibit Staphylococcus aureus Biofilm Formation and Improve Response to Antibiotics // Otto M, ed. PLoS ONE. 2012. Vol. 7(1). P. e28737. doi:10.1371/journal.pone.0028737.

74. Rasamiravaka T., Vandeputte O.M., Pottier L., et al. Pseudomonas aeruginosaBiofilm Formation and Persistence, along with the Production of Quorum Sensing-Dependent Virulence Factors, Are Disrupted by a Triterpenoid Coumarate Ester Isolated from Dalbergia trichocarpa, a Tropical Legume // Fleiszig S, ed. PLoS ONE. 2015. Vol. 10(7). P. e0132791. doi:10.1371/journal.pone.0132791.

75. Park J., Kaufmann G.F., Bowen J.P., Arbiser J.L., Janda K.D. Solenopsin A, a venom alkaloid from the fire ant Solenopsis invicta, inhibits quorum-sensing signaling in Pseudomonas aeruginosa // Journal of Infectious Diseases. 2008. Vol. 198(8). Pp. 1198-1201. doi: 10.1086/591916.

76. Walker T.S., Bais H.P., Déziel E., et al. Pseudomonas aeruginosa -plant root interactions. Pathogenicity, biofilm formation, and root exudation. // Plant Physiology. 2004. Vol. 134(1). Pp. 320-331. doi: 10.1104/pp.103.027888.

77. Girennavar B., Cepeda M.L., Soni K.A., et al. Grapefruit juice and its furocoumarins inhibits autoinducer signaling and biofilm formation in bacteria // International Journal of Food Microbiology. 2008. Vol. 125(2). Pp. 204-208. doi: 10.1016/j.ijfoodmicro.2008.03.028.

78. Zeng Z., Qian L., Cao L., et al. Virtual screening for novel quorum sensing inhibitors to eradicate biofilm formation of Pseudomonas aeruginosa // Applied Microbiology and Biotechnology. 2008. Vol. 79(1). Pp. 119-126. doi: 10.1007/s00253-008-1406-5.

79. Ding X., Yin B., Qian L., et al. Screening for novel quorum-sensing inhibitors to interfere with the formation of Pseudomonas aeruginosa biofilm // Journal of Medical Microbiology. 2011. Vol. 60 (part 12). Pp. 1827-1834. doi: 10.1099/jmm.0.024166-0.

80. Ta C.A., Freundorfer M., Mah T.F., et al. Inhibition of bacterial quorum sensing and biofilm formation by extracts of neotropical rainforest plants // Planta Medica. 2014. Vol. 80(4). Pp. 343-350.

81. Jakobsen T.H., van Gennip M., Phipps R.K., et al. Ajoene, a sulfur-rich molecule from garlic, inhibits genes controlled by quorum sensing // Antimicrobial Agents and Chemotherapy. 2012. Vol. 56(5). Pp. 2314-2325. doi: 10.1128/AAC.05919-11. 
82. Kim H.-S., Park H.-D. Ginger extract inhibits biofilm formation by Pseudomonas aeruginosa PA14 // PLoS ONE. 2013. Vol. 8(9). doi: 10.1371/journal.pone.0076106.e76106.

83. Carneiro V.A., Dos Santos H.S., Arruda F.V.S., et al. Casbane diterpene as a promising natural antimicrobial agent against biofilm-associated infections // Molecules. 2011. Vol. 16(1). Pp. 190-201. doi: 10.3390/molecules16010190.

84. Ren D., Zuo R., González-Barrios A.F., et al. Differential gene expression for investigation of Escherichia coli biofilm inhibition by plant extract ursolic acid // Applied and Environmental Microbiology. 2005. Vol. 71(7). Pp. 4022-4034. doi: 10.1128/AEM.71.7.4022-4034. 2005.

85. Vidigal P.G., Müsken M., Becker K.A., et al. Effects of Green Tea Compound Epigallocatechin-3-Gallate against Stenotrophomonas maltophilia Infection and Biofilm // Infante-Duarte C, ed. PLoS ONE. 2014. Vol. 9(4). P. e92876. doi:10.1371/journal.pone.0092876.

86. Selim S.A., Adam M.E., Hassan S.M., Albalawi A.R. Chemical composition, antimicrobial and antibiofilm activity of the essential oil and methanol extract of the Mediterranean cypress (Cupressus sempervirens L.) // BMC Complementary and Alternative Medicine. 2014. Vol. 14. P. 179. doi:10.1186/1472-6882-14-179.

87. Lee J.-H., Kim Y.-G., Yong Ryu S., Lee J. Calcium-chelating alizarin and other anthraquinones inhibit biofilm formation and the hemolytic activity of Staphylococcus aureus // Scientific Reports. 2016. Vol. 6. P. 19267. doi:10.1038/srep19267.

Поступило в редакциию 14 октября 2016 г.

После переработки 30 ноября 2016 г. 
Zhivetev M.A. ${ }^{1,2 *}$, Markova Ju.A. ${ }^{1,2,3}$, Graskova I.A. ${ }^{1,3}$ IMPACT OF PLANT EXTRACTS AND THEIR METABOLITES ON THE FORMATION OF BIOFILMS (REVIEW)

\footnotetext{
${ }^{I}$ Siberian Institute of Plant Physiology and Biochemistry, Siberian Branch of the Russian Academy of Sciences, Lermontov st.,132, Irkutsk,664033 (Russia), e-mail: nik19@mail.ru

${ }^{2}$ Irkutsk National Research Technical University, Lermontov st., 83, Irkutsk, 664074 (Russia)

${ }^{3}$ The Irkutsk Scientific Center, Siberian Branch of the Russian Academy of Sciences, Lermontov st., 134, Irkutsk, 664033 (Russia)
}

The review considered various regulators of development of bacterial biofilms. Special attention is paid to essential oils, vegetable extracts, their fractions and specific compounds of medicinal, food and forage plants. Uncovered a number of their impact mechanisms on the collective behavior of microorganisms. Substances produced by plants can provide not only a direct toxic effect on the bacterial cells, but also serve regulating of gene expression of antibiotic resistance genes and their biosynthesis, as well as a wide range of genes being activated when switching from free existence to the attached living. Considered by the activity of plant extracts and metabolites are distributed not only on gram and gram bacteria, but also on other microorganisms, including yeast, that extends the capabilities of their practical application. Synergistic effects metabolites of plants with antibiotics and their ability to effectively block quorum sensing bacteria and their adhesion, allow you to deal with plant extracts and isolated compounds of plant origin as promising to combat infectious processes caused by the ability of bacteria to form biofilms. By and large, in any of the known higher and lower plant may contain substances of antibacterial actions violating the strategy of collective behaviour of microorganisms and inhibit pathogenic bacteria colonization of tissues and cells of plant. Bactericidal, bacteriostatic and anti biofilm effects, can differ significantly even in the case of compounds of similar chemical nature and one the same substance can simultaneously serve to different regulation mechanisms.

Keywords: plant extracts, plant metabolites, effect on microorganisms, biofilms, quorum sensing.

\section{References}

1. Bogino P.C., de la Mercedes Oliva M., Sorroche F.G., Giordano W. Int. J. Mol. Sci., 2013, no. 14, pp. 15838-15859.

2. Aparna M.S., Yadav S. Dranz. J. Infect. Dis., 2008, vol. 12 (6), pp. 526-530.

3. Khrenov P.A., Chestnova T.V. Vestnik novykh meditsinskikh tekhnologii, 2013, no. 1, electronic edition. (in Russ.).

4. Il'ina T.S., Romanova Iu.M., Gintsburg A.L. Genetika, 2004, no. 40, pp. 1-12. (in Russ.).

5. Romanova Iu.M., Gintsburg A.L. Zhurnal mikrobiologii, epidemiologii i immunobiologii, 2011, no. 3, pp. 99-109. (in Russ.).

6. Gostev V.V., Sidorenko S.V. Zhurnal infektologii, 2010, vol. 2, no. 3, pp. 4-15. (in Russ.).

7. Tolordava E.R., Perepanova T.S., Egamberdiev D.K., Romanova Iu.M. Klinicheskaia laboratornaia diagnostika, 2010, no. 9, pp. 31-32. (in Russ.).

8. Golub A.V. Klinicheskaia mikrobiologiia i antimikrobnaia khimioterapiia, 2012, vol. 14, no. 1, pp. 23-29. (in Russ.).

9. González J.E., Keshavan N.D. Microbiology and Molecular Biology Reviews, 2006, vol. 70 (4), pp. 859-875.

10. Kearns D.B. Nature Reviews Microbiology, 2010, vol. 8(9), pp. 634-644.

11. Daniels R., Vanderleyden J., Michiels J. FEMS microbiology reviews, 2004, vol. 28(3), pp. 261-289.

12. Pliuta V.A. Osobennosti obrazovaniia bioplenok $i$ Quorum Sensing reguliatsiia pri deistvii antibakterial'nykh agentov: diss. ... kand. biol. nauk. [Features of biofilm formation and Quorum Sensing regulation under the action of antibacterial agents: diss. ... cand. Biol. Sciences.]. Moskva, 2014, 152 p. (in Russ.).

13. Nazzaro F., Fratianni F., Coppola R. International journal of molecular sciences, 2013, vol. 14(6), pp. 12607-12619.

14. Zhang N., Wang D., Liu Y. Plant and Soil, 2014, vol. 374 (1-2), pp. 689-700.

15. Khramova E.P., Tsybulia N.V., Chindiaeva L.N. Rastitel'nye resursy, 2013, vol. 49, pp. 598-612. (in Russ.).

16. Avdeeva E.Iu., Krasnov E.A., Semenov A.A. Khimiia rastitel'nogo syr'ia, 2015, no. 3, pp. 43-48. (in Russ.).

17. Bubenchikov R.A. Fitokhimicheskoe i farmakologicheskoe izuchenie rastenii roda fialka. Avtoref. diss. ... kand. med. nauk. [Phytochemical and pharmacological study of plants of the genus violet. Author's abstract. Diss. ... cand. Medical. Sciences]. Kursk, 2002, 23 p. (in Russ.).

18. Martynov A.M., Dargaeva T.D. Sibirskii meditsinskii zhurnal, 2009, no. 7, pp. 213-215. (in Russ.).

19. Patent 2480746 (RU). 27.04.2002. (in Russ.).

20. Nascimento P.L.A., Nascimento T.C.E.S., Ramos N.S.M., Silva G.R., Gomes J.E.G., Falcao R.E.A., Moreira K.A., Porto A.L.F., Silva T.M.S. Molecules, 2014, vol. 19, pp. 5434-5447.

21. Samoilova Z.Iu. Izuchenie antioksidantnogo deistviia rastitel'nykh ekstraktov na bakterii Escherichia coli: avtoref. diss. ... kand. biol. nauk. [The study of the antioxidant effect of plant extracts on Escherichia coli bacteria: author's abstract Diss. ... cand. Biol. Sciences]. Perm', 2009, 159 p. (in Russ.).

22. Sakihama Y., Cohen M.F., Grace S.C., Yamasaki H. Toxicology, 2002, vol. 177, pp. 67-80.

23. Ethnomedicine: a source of complementary therapeutics, ed. D. Chattopadhyay, Kerala (India): Research Signpost, 2010.

24. German A., Bochenek Zh., German A.P. Prikladnaia biokhimiia i mikrobiologiia, 2013, vol. 49, no. 5, pp. 476-480. (in Russ.).

25. Foss M.H., Eun Y.J., Weibel D.B. Biochemistry, 2011, vol. 50 (36), pp. 7719-7734.

26. Domadia P., Swarup S., Bhunia A., Sivaramon J., Dasgupta D. Biochem. Pharmacol., 2007, vol. 74 (6), pp. $831-840$.

27. Kwon J.A., Yu C.B., Park H.D. Lett. Appl. Microbiol., 2003, vol. 37 (1), pp. 61-65.

\footnotetext{
* Corresponding author.
} 
28. Dorantes L., Colmenero R., Hernandez H., Mota L., Jaramillo M.E., Fernandez E., Solano C. Intern. Food Microbiol., 2000, vol. 57 (1-2), pp. 125-128.

29. Rastogi N., Domadia P., Shetty S., Dasgubta D. Indian J. Exp. Biol., 2008, vol. 46 (11), pp. $783-787$.

30. Schaffner-Barbero C., Martin-Fontecha M., Chocon P., Andreu J.M. ACS Chem. Biol., 2012, vol. 7 (21), pp. 13301340.

31. Choo J.H., Rukayadi Y., Hwang J.K. Lett. Appl. Microbiol., 2006, vol. 42, pp. 637-641.

32. Brackman G., Hillaert U., van Calenbergh S. Res. Microbiol., 2009, vol. 160, pp. 144-151.

33. Aliyu A.B., Koorbanally N.A., Moodley B., Singh P., Chenia H.Y. Phytochemistry, 2016, vol. 126, pp. $23-33$.

34. Adonizio A.L., Downum K., Bennett B.C., Kalai M. J. of Ethnopharmacology, 2006, vol. 105, pp. 427-435.

35. Marcinkiewicz J., Strus M., Pasich E. Polskie Archiwum Medycyny Wewnętrznej, 2013, vol. 123 (6), pp. 309-313.

36. Ahmad I., Husain F.M., Maheshwari M., Zahin M. Antibiofilm Agents. Springer Berlin - Heidelberg, 2014, pp. $205-232$.

37. Jimenez-Guerrero P.-M.F.I., Sanchez-Matamoros R.C. Research in microbiology, 2013, vol. 164(7), pp. 749-760.

38. Ren D., Sims J.J., Wood T.K. Environmental Microbiology, 2001, vol. 3 (11), pp. 731-736.

39. Peters N.K., Frost J.W., Long S.R. Science, 1986, vol. 233 (4767), pp. 977-980.

40. Singh B.N., Singh B.R., Singh R.L., Prakash D., Sarma B.K., Singh H.B. Food and Chemical Toxicology, 2009, vol. 47, pp. 778-786.

41. Ardestani A., Yazdanparast R. Food Chemistry, 2007, vol. 104, pp. 21-29.

42. Bacha K., Tariku Y., Gebreyesus F., Zerihun S., Mohammed A., Weiland-Bräuer N., Schmitz R.A., Mulat M. BMC Microbiol., 2016, vol. 16, no. 1, p. 139.

43. Ilic-Tomic T., Sokovic M., Vojnovic S., Ciric A., Veljic M., Nikodinovic-Runic J., Novakovic M. Planta Med., 2017, vol. 83, pp. 117-125.

44. Sheng J.Y., Chen T.T., Tan X.J., Chen T., Jia A.Q. Bioorg. Med. Chem. Lett., 2015, vol. 25(22), pp. 5217-5220.

45. Vasavi H.S., Arun A.B., Rekha P.D. Microbiol. Immunol., 2014, vol. 58, no. 5, pp. 286-293.

46. Vasavi H.S., Arun A.B., Rekha P.D. J. Microbiol. Immunol. Infect., 2016, vol. 49, no. 1, pp. 8-15.

47. Corral-Lugo A., Daddaoua A., Ortega A., Espinosa-Urgel M., Krell T. Sci. Signal., 2016, vol. 9, no. 409, p. 1.

48. Shukla V., Bhathena Z. Scientifica (Cairo), 2016, vol. 2016, p. 5823013.

49. Lavid N., Schwartz A., Yarden O., Tel-Or E. Planta, 2001, vol. 212, pp. 323-331.

50. Hossain M.A., Lee S.J., Park J.Y., Reza M.A., Kim T.H., Lee K.J., Suh J.W., Park S.C. J. Ethnopharmacol., 2015, vol. 174, pp. 482-491.

51. Maisuria V.B., Santos Y.L.L., Tufenkji N., Déziel E. Sci. Rep., 2016, vol. 6, p. 30169.

52. Farrand S.K., Qin Y., Oger P. Methods in enzymology, 2002, no. 358, pp. 452-484.

53. Muller E., Takeda S., Shiro H. J. Infect. Dis., 1993, vol. 168, pp. 1211-1218.

54. Jagani S., Chelikani R., Kim D.S. Biofouling, 2009, vol. 25, no. 4, pp. 321-324.

55. Borges A., Saavedra M.J., Simões M. Biofouling, 2012, vol. 28, no. 7, pp. 755-767.

56. Lemos M., Borges A., Teodosio J. International Biodeterioration \& Biodegradation, 2014, no. 86, pp. $42-51$.

57. Wojnicz D., Kucharska A.Z., Sokoł-Łetowska A. Urol. Res., 2012, no. 40, pp. 683-697.

58. Zogaj X., Bokranz W., Nimtz M., Römling U. Infection and immunity, 2003, vol. 71, no. 7, pp. 4151-4158.

59. Howell A.B., Vorsa N., Marderosian A.D., Foo L.Y. New England Journal of Medicine, 1998, vol. 339, no. 15, pp. $1085-1086$.

60. Ahuja S., Kaack B., Roberts J. The Journal of urology, 1998, vol. 159, no. 2, pp. 559-562.

61. Gupta A., Dwivedi M., Mahdi A.A. Urological research, 2012, vol. 40, no. 2, pp. 143-150.

62. Åberg V., Almqvist F. Organic \& biomolecular chemistry, 2007, vol. 5, no. 12, pp. 1827-1834.

63. Abreu A.C., McBain A.J., Simoes M. Natural product reports, 2012, vol. 29, no. 9, pp. 1007-1021.

64. Al-hebshi N., Al-haroni M., Skaug N. Archives of oral biology, 2006, vol. 51, no. 3, pp. 183-188.

65. Yang Z.C., Wang B.C., Yang X.S. Colloids and surfaces B: Biointerfaces, 2005, vol. 41, no. 2, pp. $79-81$.

66. Griep M.A., Blood S., Larson M.A. Bioorganic \& medicinal chemistry, 2007, vol. 15, no. 22, pp. 7203-7208.

67. Manner S., Skogman M., Goeres D., Vuorela P., Fallarero A. International Journal of Molecular Sciences, 2013. vol. 14(10), pp. 19434-19451.

68. Kim D., Hwang G., Liu Y., Wang Y., Singh A.P., Vorsa N., et al. PLoS ONE, 2015, vol. 10(12), e0145844. doi:10.1371/journal.pone.0145844.

69. Luiz R.L.F., Vila T.V.M., de Mello J.C.P., Nakamura C.V., Rozental S., Ishida K. BMC Complementary and Alternative Medicine, 2015, vol. 15, no. 68. doi:10.1186/s12906-015-0597-4.

70. Awolola G.V., Koorbanally N.A., Chenia H., Shode F.O., Baijnath H. African Journal of Traditional, Complementary, and Alternative Medicines, 2014, vol. 11(3), pp. 124-131.

71. Lee J.-H., Regmi S.C., Kim J.-A., et al. Payne SM, ed. Infection and Immunity, 2011, vol. 79(12), pp. $4819-4827$. doi:10.1128/IAI.05580-11.

72. Rane H.S., Bernardo S.M., Howell A.B., Lee S.A. Journal of Antimicrobial Chemotherapy, 2014, vol. 69(2), pp. 428-436. doi:10.1093/jac/dkt398.

73. Quave C.L., Estévez-Carmona M., Compadre C.M., et al. Otto M, ed. PLoS ONE, 2012, vol. 7(1), e28737. doi:10.1371/journal.pone.0028737.

74. Rasamiravaka T., Vandeputte O.M., Pottier L., et al. Fleiszig S, ed. PLoS ONE, 2015, vol. 10(7), e0132791. doi:10.1371/journal.pone.0132791. 
75. Park J., Kaufmann G.F., Bowen J.P., Arbiser J.L., Janda K.D. Journal of Infectious Diseases, 2008, vol. 198(8), pp. 1198-1201. doi: 10.1086/591916.

76. Walker T.S., Bais H.P., Déziel E., et al. Plant Physiology, 2004, vol. 134(1), pp. $320-331$. doi: 10.1104/pp.103.027888.

77. Girennavar B., Cepeda M.L., Soni K.A., et al. International Journal of Food Microbiology, 2008, vol. 125(2), pp. 204-208. doi: 10.1016/j.ijfoodmicro.2008.03.028.

78. Zeng Z., Qian L., Cao L., et al. Applied Microbiology and Biotechnology, 2008, vol. 79(1), pp. $119-126$. doi: 10.1007/s00253-008-1406-5.

79. Ding X., Yin B., Qian L., et al. Journal of Medical Microbiology, 2011, vol. 60 (part 12), pp. $1827-1834$. doi: 10.1099/jmm.0.024166-0.

80. Ta C.A., Freundorfer M., Mah T.F., et al. Planta Medica, 2014, vol. 80(4), pp. 343-350.

81. Jakobsen T.H., van Gennip M., Phipps R.K., et al. Antimicrobial Agents and Chemotherapy, 2012, vol. 56(5), pp. 2314-2325. doi: 10.1128/AAC.05919-11.

82. Kim H.-S., Park H.-D. PLoS ONE, 2013, vol. 8(9). doi: 10.1371/journal.pone.0076106.e76106.

83. Carneiro V.A., Dos Santos H.S., Arruda F.V.S., et al. Molecules, 2011, vol. 16(1), pp. $190-201$. doi: 10.3390/molecules16010190.

84. Ren D., Zuo R., González-Barrios A.F., et al. Applied and Environmental Microbiology, 2005, vol. 71(7), pp. 40224034. doi: 10.1128/AEM.71.7.4022-4034. 2005.

85. Vidigal P.G., Müsken M., Becker K.A., et al. Infante-Duarte C, ed. PLoS ONE, 2014, vol. 9(4), e92876. doi:10.1371/journal.pone.0092876.

86. Selim S.A., Adam M.E., Hassan S.M., Albalawi A.R. BMC Complementary and Alternative Medicine, 2014, vol. 14, p. 179. doi:10.1186/1472-6882-14-179.

87. Lee J.-H., Kim Y.-G., Yong Ryu S., Lee J. Scientific Reports, 2016, vol. 6, p. 19267. doi:10.1038/srep19267.

Received October 14, 2016.

Revised November 30, 2016 